\title{
Structure of mass and momentum fields over a model aggregation of benthic filter feeders
}

\author{
J. P. Crimaldi ${ }^{1}$, J. R. Koseff ${ }^{2}$, and S. G. Monismith ${ }^{2}$ \\ ${ }^{1}$ Department of Civil and Environmental Engineering, University of Colorado, Boulder, CO, 80309-0428, USA \\ ${ }^{2}$ Department of Civil and Environmental Engineering, Stanford University, Stanford, CA, 94305-4020, USA
}

Received: 18 January 2007 - Published in Biogeosciences Discuss.: 9 February 2007

Revised: 19 April 2007 - Accepted: 19 April 2007 - Published: 16 May 2007

\begin{abstract}
The structure of momentum and concentration boundary layers developing over a bed of Potamocorbula amurensis clam mimics was studied. Laser Doppler velocimetry (LDV) and laser-induced fluorescence (LIF) probes were used to quantify velocity and concentration profiles in a laboratory flume containing 3969 model clams. Model clams incorporated passive roughness, active siphon pumping, and the ability to filter a phytoplankton surrogate from the flow. Measurements were made for two crossflow velocities, four clam pumping rates, and two siphon heights. Simultaneous use of LDV and LIF probes permited direct calculation of scalar flux of phytoplankton to the bed. Results show that clam pumping rates have a pronounced effect on a wide range of turbulent quantities in the boundary layer. In particular, the vertical turbulent flux of scalar mass to the bed was approximately proportional to the rate of clam pumping.
\end{abstract}

\section{Introduction}

Shallow estuarine communities are commonly dominated by suspension feeders that filter phytoplankton and other particles from the overlaying flow. The extent to which these feeders can effectively filter the bulk phytoplankton biomass depends on the vertical distribution and flux of phytoplankton in the water column. Phytoplankton generally reproduce near the surface where there are high levels of incident light. Density stratification or low levels of vertical mixing can isolate phytoplankton in the upper layers of the water column (Koseff et al., 1993). On the other hand, turbulent mixing can distribute phytoplankton throughout the water column, where they become accessible to benthic grazers. But grazing acts as a near-bed sink of phytoplankton,

Correspondence to: J. P. Crimaldi

(crimaldi@colorado.edu) and, in the absence of sufficient phytoplankton replenishment from above through mixing, can produce a phytoplanktondepleted, near-bed region called a concentration boundary layer. The severity of this concentration boundary layer depends on a balance between the rate at which grazers remove phytoplankton and the rate at which phytoplankton is delivered to the bed by turbulent mixing processes. The nature of the turbulence, and hence of the vertical mixing, depends on tidal energy, waves, bed geometry, and the presence of the benthic feeders themselves, whose geometric roughness and siphonal currents can alter the flow.

In the present study, we investigate how aggregations of benthic suspension feeders can alter the structure of both the overlaying momentum and concentration fields. The physical roughness associated with benthic communities alters the turbulent velocity field above them (Butman et al., 1994; van Duren et al., 2006), significantly enhancing both turbulence intensities and Reynolds stresses. Active siphonal currents associated with filter feeding also impact the overlaying flow structure (Ertman and Jumars, 1988; Larsen and Riisgard, 1997), and have been shown to enhance turbulence intensities (Monismith et al., 1990; van Duren et al., 2006). The presence of suspension feeders also changes the structure of the concentration field above them (O'Riordan et al., 1993; Widdows and Navarro, 2007). Near-bed concentrations are reduced by the filtering action of the community, but this effect can be mitigated by additional mixing due to both physical roughness and siphonal pumping.

We used model aggregations of the Asian clam Potamocorbula amurensis for this study. San Francisco Bay in California, USA is abundantly populated by this invasive species (Carlton et al., 1990), and it has become clear that the grazing pressure exerted by these clams alters the dynamics of phytoplankton blooms in the San Francisco Estuary. The goal of the study is to quantify changes to the momentum and concentration fields produced by the passive siphon roughness and active siphonal pumping of the clam aggregations.

Published by Copernicus Publications on behalf of the European Geosciences Union. 


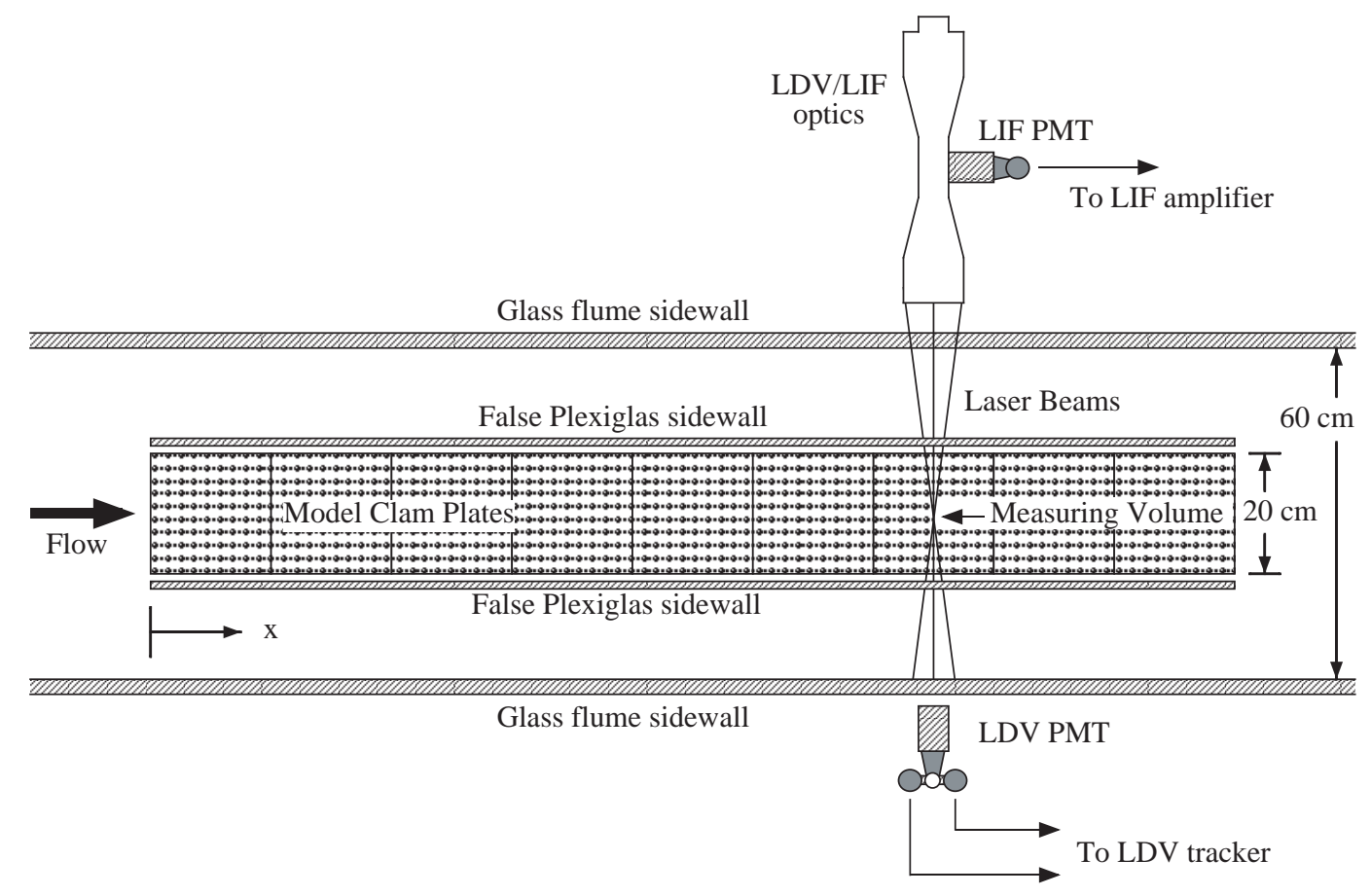

Fig. 1. Top view of the flume test section showing the model clam plates, false sidewalls, and the LDV/LIF optical measurement system.

\section{Methods}

\subsection{Flume}

The experiments were performed in an open-channel, recirculating flume in the Environmental Fluid Mechanics Laboratory at Stanford University. The flume is constructed of stainless steel and Plexiglas, with glass sidewalls in the test section to reduce laser refraction at the glass/water interface. The flume capacity in normal operation is approximately 8000 liters. A centrifugal pump commanded by a digital frequency controller draws water from a downstream reservoir and charges a constant-head tank upstream of the flume. An overspill pipe returns excess water from the constanthead tank back to the downstream reservoir. Water from the constant-head tank enters the flume through a full-width diffuser and then passes through three stilling screens with decreasing coarseness to remove any large-scale structure in the flow and homogenize the turbulence. The flow then passes through a 6.25:1, two-dimensional contraction and enters a rectangular channel. A 3-mm rod spanning the flume floor at the beginning of the channel section trips the boundary layer $2 \mathrm{~m}$ upstream of the test section. The flow passes through the test section, then through an exit section, and finally over an adjustable weir back into the downstream reservoir. Freestream velocities in the test section of $10 \mathrm{~cm} \mathrm{~s}^{-1}$ to $40 \mathrm{~cm} \mathrm{~s}^{-1}$ are used for this study.

The test section is $3 \mathrm{~m}$ long and $0.6 \mathrm{~m}$ wide, with a rectangular cross section and a nominal flow depth of $25 \mathrm{~cm}$
(Fig. 1). In the middle of the test section floor is a $1.8-\mathrm{m}$ long by $20-\mathrm{cm}$ wide, removable section that can accommodate either a set of model clam plates or a single smooth plate for baseline flow measurements. A pair of thin Plexiglas sidewalls border the lateral edges of the model clam plates. These false walls extend vertically from the bed through the free surface and act as symmetry planes to effectively model a wide bed of clams. The boundary layers developing on the false vertical walls grow to only about $1 \mathrm{~cm}$ thick at the downstream edge, and thus have little effect on flow over the plates (Fig. 2). The flow is quite uniform across the inner test section, with no significant variation or secondary flow structure.

Measurements for this study were made on the flume centerline over the model clam plates (or over a smooth plate for baseline measurements). The streamwise location of the measurements is denonted by $x$, which is measured from the upstream edge of the plates (Fig. 1). The plates extend from $x=0$ at the upstream edge to $x=180 \mathrm{~cm}$ at the downstream edge.

\subsection{Model Clams}

Models of clam aggregations were placed in the removable floor section of the flume. The models mimicked three clam feautures: (1) the physical roughness associated with siphons that are raised into the flow, (2) the incurrent and excurrent siphonal flows associated with filter feeding, and (3) the ability of the clams to filter mass from the flow. Two 


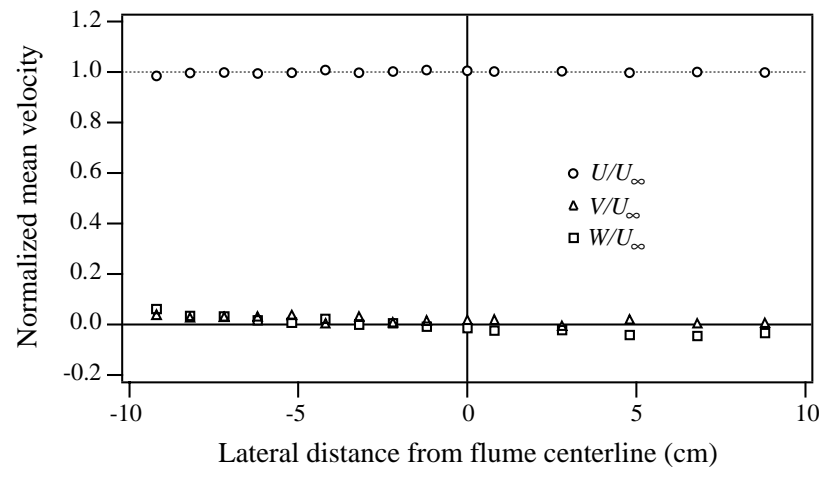

Fig. 2. Lateral profiles over a smooth bed at $z=15 \mathrm{~cm}$ of mean streamwise $(U)$, lateral $(V)$, and vertical $(W)$ velocities, normalized by the mean free stream velocity $U_{\infty}$. The false sidewalls are located at 10 and $-10 \mathrm{~cm}$ from the centerline.

types of clam models were built, one with raised siphons (that were therefore rough) and one with flush siphons (that presented a smooth surface except for the presence of the siphon orifices). Tests were run with only one type of clam model (siphons raised or siphons flush) present in the flume at one time. Each model type consisted of nine identical 20$\mathrm{cm} \times 20$ - $\mathrm{cm}$ square plates that fill the $1.8 \mathrm{~m}$ long cutout in the flume floor. Each plate contains a $21 \times 21$ array of individual clam siphon pairs (inhalant plus exhalant), resulting in 441 clams per plate, and a total of 3969 clams in the strip of nine plates. The clam models, while idealized, were fullscale representations of their biological counterparts, with regard both to siphonal dimension and pumping rates. Dimensions and flow rates were based on observations of real Potamocorbula amurensis clams made by Cole et al. (1992) and Thompson (personal comm.).

Clam models with raised and flush siphons had the same inhalant and exhalant orifice geometry (Fig. 3), but the latter did not protrude into the flow. Thus, the flush siphon model for an individual clam consisted simply of a pair of holes in a smooth plate through which siphonal currents flowed.

Models of individual clams were arrayed on plates placed in the flume test section (Fig. 4). This geometry was repeated across the entire array of 3969 clam models for both the raised and flush siphon model types.

Model clam plates were cast in a mold using a firm rubber; details of the construction process are given by O'Riordan (1993). The interior of the plates included a series of channels that linked all of the incurrent siphons together and all of the excurrent siphons together. The back of each plate had a pair of outlets: one for all incurrent siphons, and one for all excurrent siphons. Irregularities in the casting process led to variations in the flow rates of individual clams. The measured average deviation of the vertical excurrent velocities across a row of individual clams was approximately $25 \%$ of the mean. Although this was not an intentional feature of the design, it is likely more representative of the real-world situation than uniform flow.

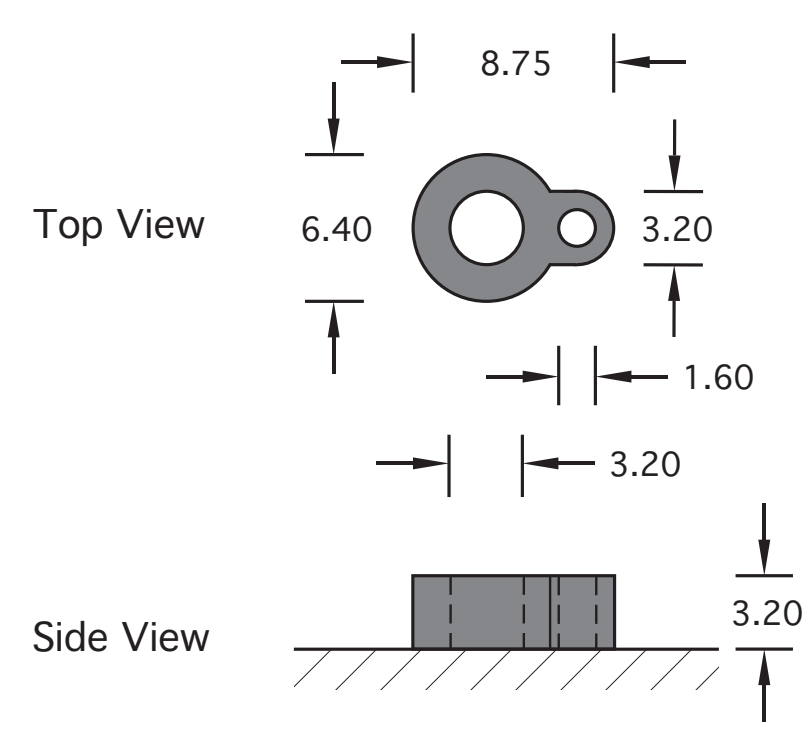

Fig. 3. Top and side views of a single model clam siphon pair in the raised position, with the rubber siphon material shown in gray. The exhalant and inhalant siphons (with diameters of $1.6 \mathrm{~mm}$ and $3.2 \mathrm{~mm}$, respectively) are shown as white circles in the top view, and as dashed lines in the side view. The side view shows that the raised siphon models protrude $3.2 \mathrm{~mm}$ into the flow. The overlaying boundary layer flow is from left to right in the figure. Dimensions are in $\mathrm{mm}$.

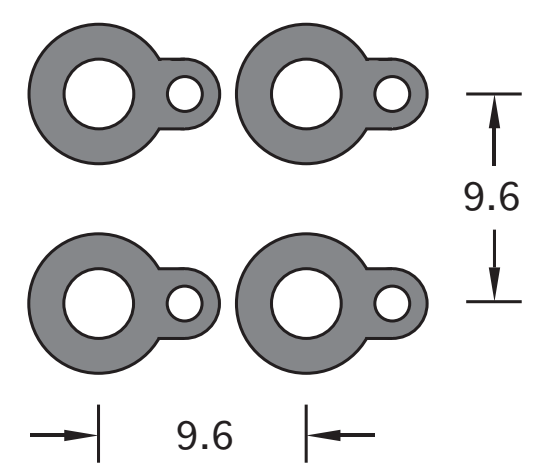

Fig. 4. Top view of a $2 \times 2$ array of model clam siphon pairs showing the clam spacing used for the study. The resulting clam array consisted of 3969 siphon pairs in a $21 \times 189$ pattern. The overlaying boundary-layer flow is from left to right in the figure. Dimensions are in $\mathrm{mm}$.

Filter feeders inhale phytoplankton-laden fluid through their incurrent siphons and then exhale fluid with some fraction of the phytoplankton removed through their excurrent siphons. Thus, while the volume of water entering and leaving the clam is constant, the amount of suspended scalar mass (e.g. phytoplankton) is not. We model this concentration change by labeling the excurrent flows with a fluorescent dye. The model clams inhale ambient water from the flume, 


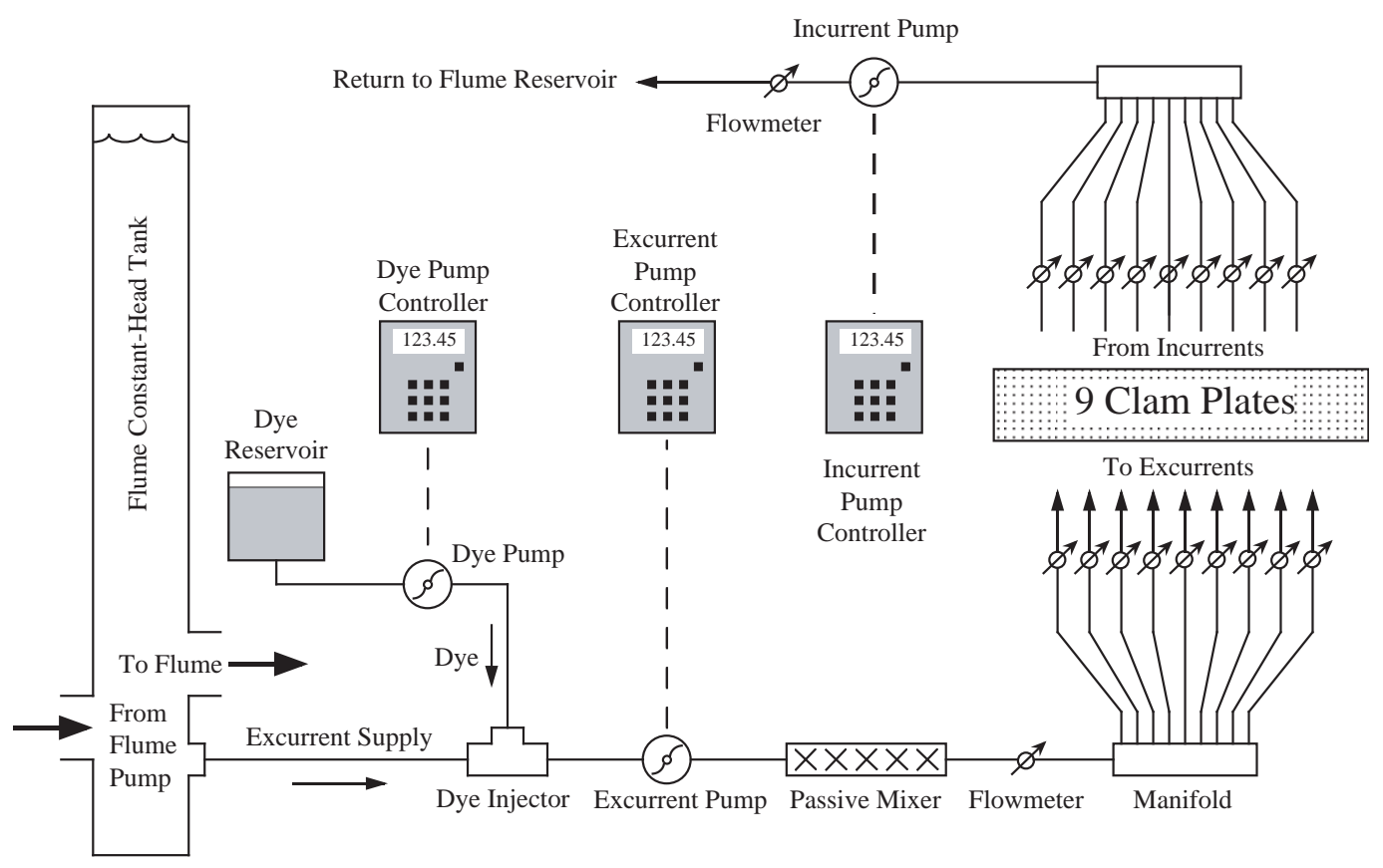

Fig. 5. Schematic of the plumbing system responsible for driving the incurrent and excurrent siphon flows, and for dosing the excurrent flows with fluorescent dye. The bottom half of the figure is the excurrent system, and the top half is the incurrent system A total of 3969 model clam siphon pairs (grouped in nine plates) were driven by this system.

but they exhale water that has a known concentration of dye. Thus, in our system, clear fluid respresents phytonplanktonladen water in the real system, and dyed fluid respresents water in the real system that has had phytoplankton filtered from it. This inverse system, which was first used by Monismith et al. (1990) and then later by O'Riordan (1993) is advantageous because smaller amounts of dye are used.

Excurrent flows consisted of ambient flume fluid with a dose of dye added to it (Fig. 5). This dosing process was done continually in real-time as the experiment was conducted. An electronically controlled centrifugal pump drew ambient fluid from the flume's constant-head tank into the excurrent supply line. The fluid in the constant-head tank was well mixed and had the same background dye concentration as the fluid that was about to enter the flume. An electronically controlled gear pump then pumped concentrated dye from a 20 -liter reservoir into to the excurrent stream. The concentrated dye entered the excurrent stream via the dye injector, and was then mixed into the excurrent supply first by passing through the centrifugal excurrent supply pump, and then through an in-line static mixer. A flow meter measured total excurrent supply flow rate, and a manifold split the supply into nine streams. Individual flow meters ensured that the nine streams had equal flow rates. Each of the nine streams passed into one of the nine model clam plates, where a series of internal channels routed excurrent fluid to each one of the 441 excurrent jets in each plate. A small portion of the excurrent stream was diverted to the calibration jet for use as a reference for calibrating the LIF probe.
Incurrent flows were generated by a similar system, but without dye injection. An electronically controlled centrifugal pump drew fluid in through the incurrent siphon orifices while nine flowmeters ensured that each of the nine model clam plates had the same incurrent flow rate. A manifold then combined the nine incurrent streams, and the resulting stream returned into the flume reservoir downstream of the flume test section. There was a great deal of turbulence in the flume reservoir (generated by the plunging action of the flume flow spilling over the weir), and this turbulence constantly mixed the fluid in the reservoir. The reservoir therefore served as a well mixed source of fluid for the flume pump and the excurrent supply pump.

The concentration of background dye in the flume grew with time due to the constant dosing of the excurrent flows. The system was designed such that this concentration growth was extremely linear in time (Crimaldi, 1998). Excurrent flows contained a fixed amount of dye added on top of the existing background flume concentration, so the difference between the background concentration and the the excurrent concentration remained constant with time.

\subsection{Instrumentation}

\subsubsection{Velocity measurements}

A Dantec, two-component, laser-Doppler velocimeter (LDV) was used to measure velocities. This instrument was operated in tandem with a laser-induced fluorescence (LIF) probe 


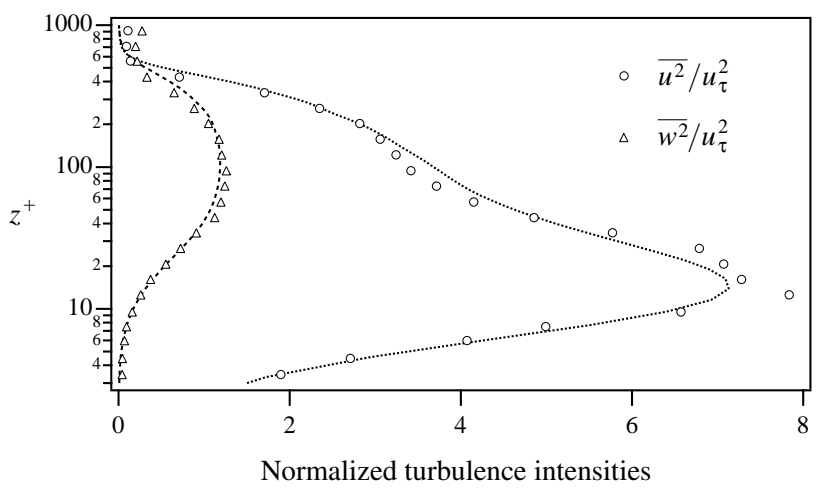

Fig. 6. Normalized streamwise $(u)$ and vertical $(w)$ turbulence intensities. Symbols are LDV data at $\operatorname{Re}_{\theta}=1320$, and lines are corresponding DNS results at $\operatorname{Re}_{\theta}=1410$ from Spalart (1988).

to measure mass fluxes. The LDV was driven with an argonIon laser operated in the $514.5 \mathrm{~nm}$ single-line mode, with a nominal output of $1.0 \mathrm{~W}$. The measuring volume was elliptical in shape, with the long axis oriented in the crosschannel direction. The dimensions of the measuring volume (to the $\mathrm{e}^{-2}$ intensity contour) were approximately $0.1 \mathrm{~mm}$ in the vertical and streamwise directions, and $1 \mathrm{~mm}$ in the crosschannel direction. The smallest scales of motion in the flows measured in this study can be determined by estimating the Kolmogorov scale as (Tennekes and Lumley, 1972)

$\eta_{K} \approx\left(\frac{\kappa z v^{3}}{u_{\tau}^{3}}\right)^{\frac{1}{4}}$

where $\kappa$ is the Kolmogorov constant, $z$ is distance from the bed, $v$ is the viscosity, and $u_{\tau}$ is the shear velocity. The smallest value of $\eta_{K}$ for the flows in this study (corresponding to $u_{\tau}=1.7 \mathrm{~cm} \mathrm{~s}^{-1}$ and $z=0.1 \mathrm{~cm}$ ) was approximately $0.1 \mathrm{~mm}$. Although this value of $\eta_{K}$ is comparable to the dimension of the measuring volume in the vertical and streamwise directions, it is smaller than the dimension in the cross-flow direction. Nonetheless, the LDV easily captures the larger scales responsible for the transport of mass and momentum. The LDV laser and optics were mounted on a motorized, computer-controlled three-axis traverse which permitted the LDV measuring volume to be positioned anywhere within the test section. The traverse system was accurate to within approximately $200 \mu \mathrm{m}$.

For validation purposes, LDV measurements of boundary layer turbulence were taken in the flume over a smooth plate that was installed in the same location where the model clam plates were later installed. The LDV results were then compared with direct numerical simulations (DNS) of boundary layer turbulence over a smooth bed by Spalart (1988). Data were recorded at 23 logarithmically-spaced vertical stations between $z=0.7 \mathrm{~mm}$ and $z=180 \mathrm{~mm}$, measured from the bed. Approximately $20 \mathrm{~min}$ of velocity data were recorded at each

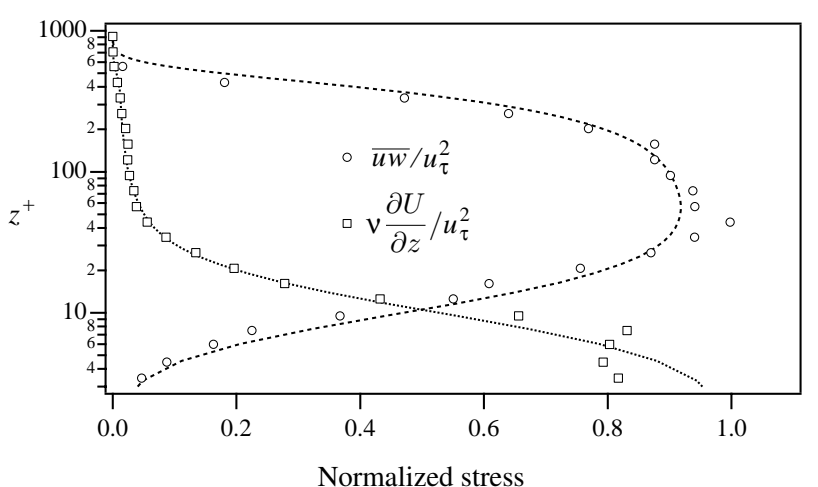

Fig. 7. Normalized Reynolds and viscous stresses. Symbols are LDV data at $\operatorname{Re}_{\theta}=1320$, and lines are corresponding DNS results at $\operatorname{Re}_{\theta}=1410$ from Spalart (1988).

station, at a sample rate of $80 \mathrm{~Hz}$. The mean free stream velocity was $U_{\infty}=11.6 \mathrm{~cm} \mathrm{~s}^{-1}$, which resulted in a calculated momentum-thickness Reynolds number of $\operatorname{Re}_{\theta}=1320$. We compared the data to Spalart's DNS results simulated at $\operatorname{Re}_{\theta}=1410$. Although the Reynolds numbers differ by $6 \%$, the variation of normalized turbulence parameters with $\operatorname{Re}_{\theta}$ is quite weak, enabling a valid comparison.

Turbulence intensities (Fig. 6) were normalized by the square of the shear velocity $u_{\tau}$ that was obtained by fitting the mean velocity profile to the law of the wall. The agreement between the LDV results and DNS calculations by Spalart (1988) was excellent for both the turbulence intensities and the viscous and turbulent stress profiles (Fig. 7).

\subsubsection{Concentration measurements}

We developed a laser-induced fluorescence (LIF) probe to make non-intrusive measurements of dye concentrations in the flow above model clam beds. The LIF probe used the same measuring volume as the LDV, ensuring that the velocity and concentration measurements were made in the same location. This is particlarly important for the scalar flux measurements, which resulted from correlations of velocity and concentration measurements. The laser light in the combined LDV/LIF measuring volume was absorbed by fluorescent dye in the flow and re-emitted at a different wavelength. The fluoresced light was optically filtered and converted to a electrical current with a photomultiplier tube (PMT). Finally, the current is converted to a voltage using an ideal currentto-voltage converter.

Because the dye fluoresces in an omni-directional pattern, we were able to place the LIF receiving optics in the backscatter configuration without any loss of signal (as opposed to the LDV receiving optics, which were placed preferentially in the strong forward-scatter lobes). The LIF receiving optics and the LIF PMT were mounted directly within the LDV front optics (using a backscatter module intended for 


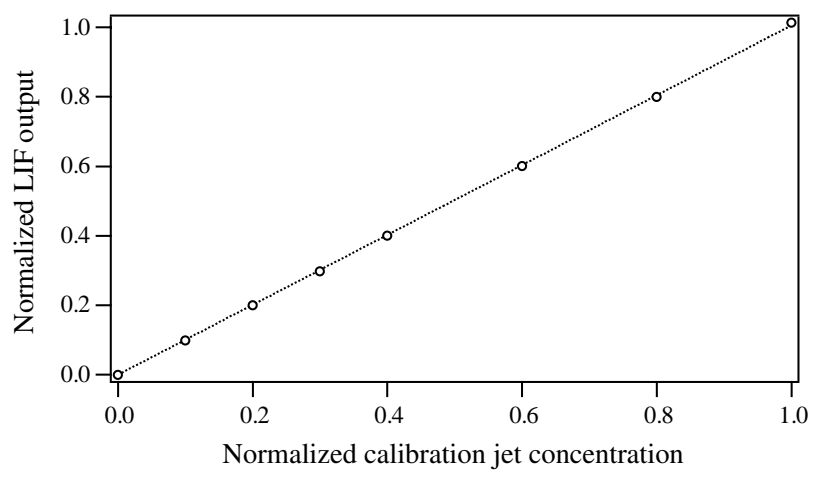

Fig. 8. Normalized calibration curve for the LIF probe showing the linear system response.

making backscatter LDV measurements). Thus, the receiving optics for the LIF automatically moved with the measuring volume as the LDV/LIF system was traversed throughout the test section of the flume, maintaining consistent alignment. The PMT for the LIF had a pinhole section that masked stray light from anywhere other than the measurement volume. More details on construction and operation of the LIF probe are given by Crimaldi (1998).

The smallest scalar fluctuations in a flow occur at the scale at which viscous diffusion acts to smooth any remaining concentration gradients. Batchelor (1959) defines this scale as

$\eta_{B}=\eta_{K} \operatorname{Pr}^{-1 / 2}$

where Pr is the Prandtl number. According to Barrett (1989), the Prandtl number for Rhodamine 6G, the dye used in the study, is 1250 . Therefore, the smallest concentration scales $\eta_{B}=3 \mu \mathrm{m}$ were about 35 times smaller than the smallest scales of motion $\eta_{K}$. Thus, the LIF probe could not resolve the smallest scales of motion present in the studied flows. However, the LIF probe could easily measure the larger concentration scales that are responsible for the vast majority of the scalar flux.

To validate the LIF probe, we measured known dye concentrations in the potential core of a jet flowing from a $7.5 \mathrm{~mm}$ diameter calibration tube within the flume test section. LIF measurements of the jet fluid were made $1 \mathrm{~mm}$ downstream of the jet orifice $(x / D=0.13)$, which ensured that the measuring volume was well within the potential core of the jet. Eight different dye concentrations ranging from 0 to $100 \mathrm{ppb}$ were pumped through the jet, and the resulting LIF data were linear (Fig. 8).

Calibration jet concentrations were normalized by the maximum value used in the test $(100 \mathrm{ppb})$. LIF output was normalized so that the output from the $40 \mathrm{ppb}$ jet was 0.4. A least-squares estimate of the slope of the line was $1.006 \pm 0.003$. The actual dye concentrations used in the measurements over the model clams rarely exceeded $5 \mathrm{ppb}$, well within the demonstrated range of linearity of the LIF probe. The time response of the LIF probe is extremely fast; the time constants associated with the dye fluorescence, with the PMT, and with the LIF signal amplifier are extremely small relative to the time scales of turbulent motion in this flow.

During experiments over the model clams, the LIF calibration jet remained in the flume, positioned above the measurement region in the free stream of the flow. A small portion of the dyed flow mixed for the excurrent supply was diverted through the calibration jet. The LIF probe was periodically positioned in the free stream and behind the calibration jet during experiments to maintain the probe calibration as background and excurrent concentrations rose during the experiments due to dye accumulation in the flume.

\subsubsection{Concentration normalization}

As discussed earlier, a known concentration of dye was continuously added to the excurrent jets. The dyed fluid represented filtered fluid devoid of phytoplankton, and fluid without dye (other than the background dye) represented phytoplankton-laden fluid. Using the LIF probe, we calculated a nondimensional concentration in this "inverse" system as

$C_{\mathrm{inv}}^{*}=\frac{C-C_{B}}{C_{E}-C_{B}}$,

where $C$ is the output of the LIF probe at the measurement location, $C_{B}$ is the output due to the background dye (measured in the free stream), and $C_{E}$ is the output of pure excurrent fluid (measured using the calibration jet). To put this "inverse" measurement in a more intuitive framework, we then defined a complementary nondimensional concentration

$C^{*}=1-C_{\mathrm{inv}}^{*}$

such that $C^{*}=1$ now corresponded (in the real system) to fluid with full phytoplankton load, and $C^{*}=0$ corresponded to fluid that had its entire phytoplankton concentration removed by filtration. These nondimensional concentrations could be converted to dimensional concentrations for a real system by considering the ambient phytoplankton concentration and the filtering efficiency of the bivalve.

\section{Results}

Vertical profiles of velocity and concentration data were taken for two crossflow velocities and four clam pumping rates, for each of the two clam model types (Table 1). For each vertical profile, simultaneous LDV and LIF data were acquired at approximately 20 vertical stations. The stations were logarithmically spaced, usually starting at $z=0.5$, and ending at $z=120 \mathrm{~mm}$. Typically, 100000 samples of data were acquired at approximately $80 \mathrm{~Hz}$ from each LDV channel and from the LIF probe for each vertical station, although 
Table 1. Parameters varied in the experiments.

\begin{tabular}{lcll}
\hline Parameter & Symbol & Values & Comments \\
\hline Free stream velocity & $U_{\infty}$ & $10,40 \mathrm{~cm} \mathrm{~s}^{-1}$ & \\
Clam pumping rate & $Q$ & $0,0.030,0.045,0.060 \mathrm{ml} \mathrm{s}^{-1}$ & rate per clam \\
Clam siphon height & $h_{s}$ & $0,3.2 \mathrm{~mm}$ & "flush" and "raised" in text \\
\hline
\end{tabular}

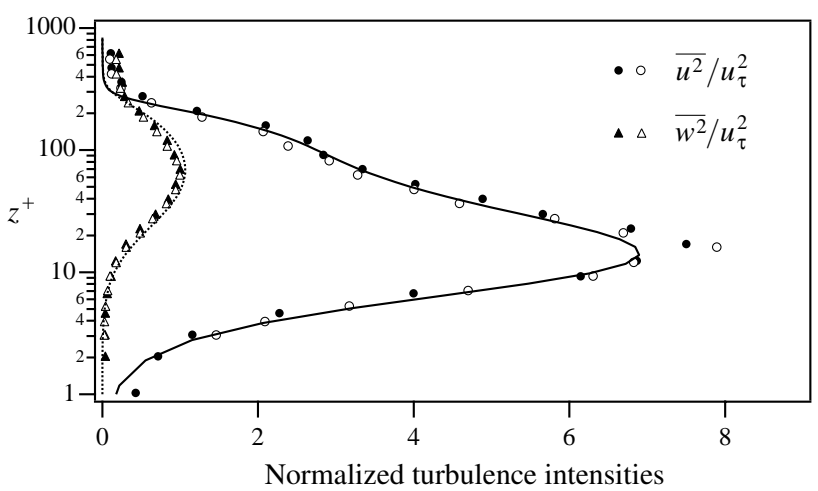

Fig. 9. Comparison of streamwise and vertical turbulence intensities for flow over non-pumping flush siphon orifices (closed symbols) with flow over a smooth plate (open symbols).

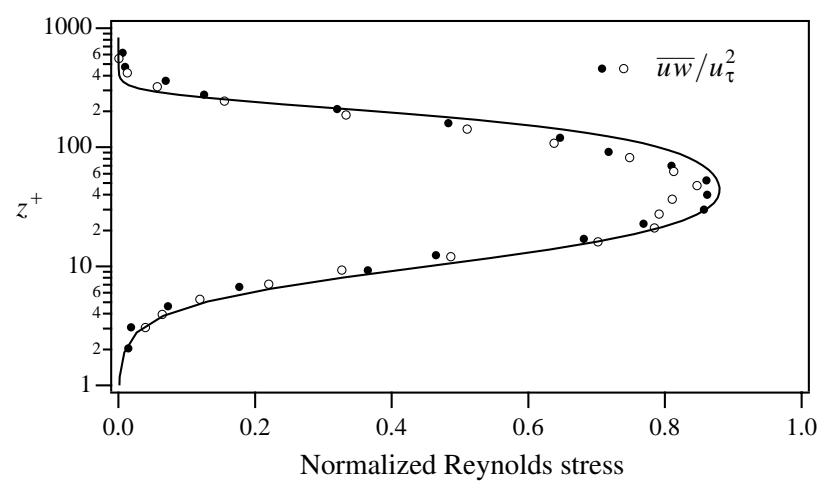

Fig. 10. Comparison of Reynolds stress correlations for flow over non-pumping flush siphon orifices (closed symbols) with flow over a smooth plate (open symbols). The lines are DNS results by Spalart (1988) at $\operatorname{Re}_{\theta}=670$.

shorter records were used near the upper edge of the boundary layer where the variance of the signals was small.

Results presented in this paper focus on perturbations made to the momentum and scalar concentration fields by the presence of the clams. These perturbations come from two sources: the presence of roughness (in the case of the model clams with raised siphons), and the presence of siphonal currents and filtering.

The flush siphonal orifices without clam pumping did not alter the flow (Figs. 9 and 10). The data shown in these (a) siphons flush

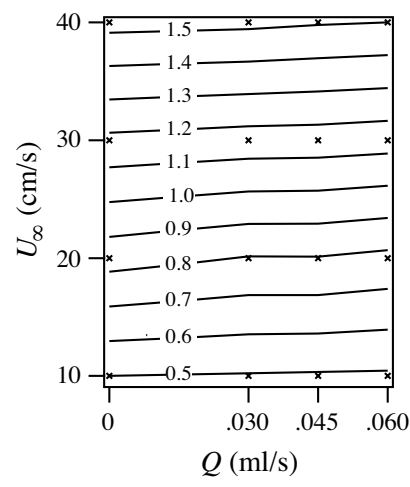

(b) siphons raised

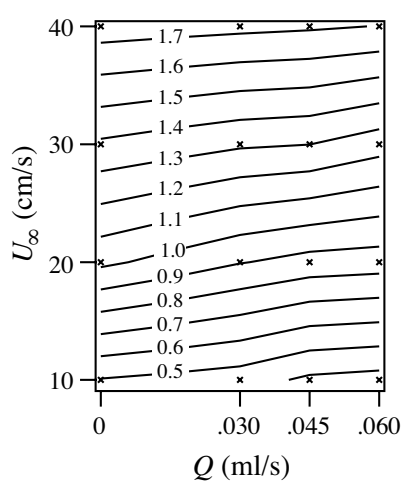

Fig. 11. Contours of shear velocity $u_{\tau}$ as a function of free stream velocity $U_{\infty}$ and clam pumping rate $Q$ for flow over (a) flush siphons and (b) raised siphons. Units for $u_{\tau}$ contours are $\mathrm{cm} \mathrm{s}^{-1}$.

two figures compares the boundary-layer flow over a smooth plate with the flow over the flush clam models, with no siphonal currents. Both experiments were performed with a free stream velocity of $U_{\infty}=10 \mathrm{~cm} \mathrm{~s}^{-1}$, corresponding to $\operatorname{Re}_{\theta}=560$. Results show that the flow over the flush siphon orifices was indistinguishable from flow over the smooth plate. Thus, the perturbations to the flow demonstrated later are due only to the presence of siphon roughness and/or siphonal pumping.

Shear velocity $u_{\tau}$ is a measure of the bed shear stress $\tau_{w}$, where $u_{\tau}=\left(\tau_{w} / \rho\right)^{1 / 2}$. As is typical in turbulent boundary layer flows, $u_{\tau}$ increases with the free stream velocity, $U_{\infty}$. The presence of the raised siphons produced an increase in $u_{\tau}$ at any given value of $U_{\infty}$ as compared to the flush siphons (Fig. 11). Siphonal pumping caused only modest increase in $u_{\tau}$, although the the increase was more pronounced (i.e., the slope of the contours was greater) for the raised siphon clam models at low free stream velocities.

\subsection{Profiles}

Figures $12-18$ present vertical profiles of velocity and concentration data in a common figure format. Because the influence of the clams is greatest in the near-bed region, distance from the bed (the vertical axis in the plots) is shown on a logarithmic scale. Each figure contains four plots 

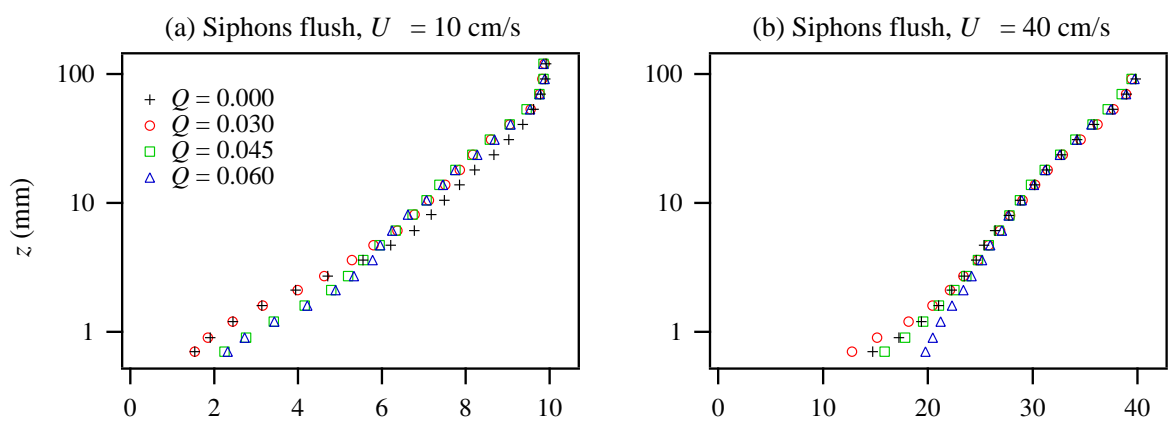

(c) Siphons raised, $U_{\infty}=10 \mathrm{~cm} / \mathrm{s}$

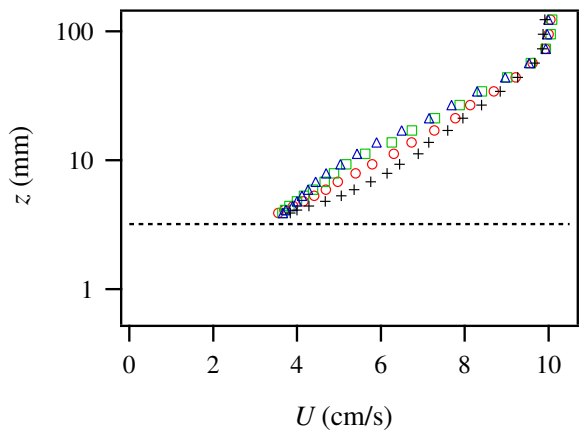

(d) Siphons raised, $U_{\infty}=40 \mathrm{~cm} / \mathrm{s}$

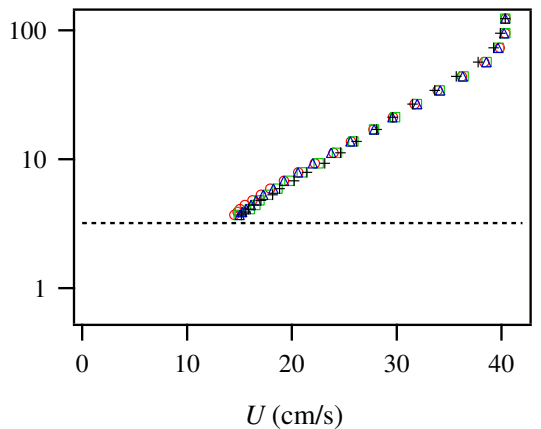

Fig. 12. Effect of clam pumping $Q$ on vertical profiles of mean streamwise velocity $U$ for different combinations of free stream velocity $U_{\infty}$ and siphon roughness. The left and right columns correspond to $U_{\infty}=10 \mathrm{~cm} \mathrm{~s}^{-1}$ and $U_{\infty}=40 \mathrm{~cm} \mathrm{~s}^{-1}$, respectively. The top and bottom rows correspond to siphons flush $\left(h_{s}=0\right)$ and raised $\left(h_{s}=3.2 \mathrm{~mm}\right)$, respectively. The bottom row plots contain a horizontal dotted line at $z=h_{s}=3.2 \mathrm{~mm}$ to denote the location of the raised siphon tops (below which data could not be acquired due to optical occlusion of the instruments). Each plot contains color-coded profiles for each of the different values of clam pumping $\left(Q=0,0.030,0.045\right.$, and $\left.0.060 \mathrm{ml} \mathrm{s}{ }^{-1}\right)$.

representing different combinations of free stream velocity $U_{\infty}$ and siphon position (flush or raised). For profiles of concentration-related quantities, there is no data for the $Q=0$ case since clam pumping is required for concentration measurements.

The influence of clam pumping on mean velocity $U$ was small and limited to the near-bed region (Fig. 12). The effect was largest for the slow $\left(U_{\infty}=10 \mathrm{~cm} \mathrm{~s}^{-1}\right)$ flow over raised siphons, where near-bed values of $U$ were retarded as $Q$ increased. This was consistent with the $u_{\tau}$ contours in Fig. 11, where the greatest sensitivity to changes in wall stress were seen for slow flows over raised siphons. For flush siphons or faster flows, the effect of $Q$ on $U$ was negligible beyond a few millimeters from the bed.

For the slow flow with flush siphons, clam pumping attenuated the streamwise turbulence intensities (expressed as the variance $\overline{u u}$ ) in a narrow region centered around $z=4 \mathrm{~mm}$ (Fig. 13a). This corresponds to the height at which the vertical excurrent jets achieve a horizontal trajectory after being bent over by the crossflow (see Fig. 4 in O'Riordan et al., 1995). Since the excurrent jets were laminar, streamwise turbulence intensities were locally reduced. The effect is similar for the fast flow case (Fig. 13b), but the attenuation was closer to the bed as the jets were bent over more rapidly by the stronger crossflow. For the slow flow over raised siphons (c), there was a similar near-bed attenuation by the clam pumping, but it was now accompanied by a strong enhancement further from the bed. Finally, for the fast flow over the raised siphons (d), the effect of clam pumping was minimal as the turbulence intensities were dominated by the flow and roughness.

The effect of clam pumping on vertical turbulence intensities is opposite from that seen for the horizontal streamwise intensities (Fig. 14). The vertical energy imparted by the incurrent and excurrent flows enhanced the vertical turbulence intensities. The effect was strongest for the slow flows $(a, c)$ where the relative strength of the clam pumping was stronger. In these cases, the influence of the pumping extended deep into the boundary layer. For the faster flows $(b, d)$ the effect was minimal except close to the bed.

The presence of roughness due to the raised siphons produced increased Reynolds stress relative to the flush siphon case, especially for the fast flow cases (Fig. 15). Clam pumping also produced an increase in Reynolds stress, with the effect more dramatic at slower flows and over the raised siphons. 

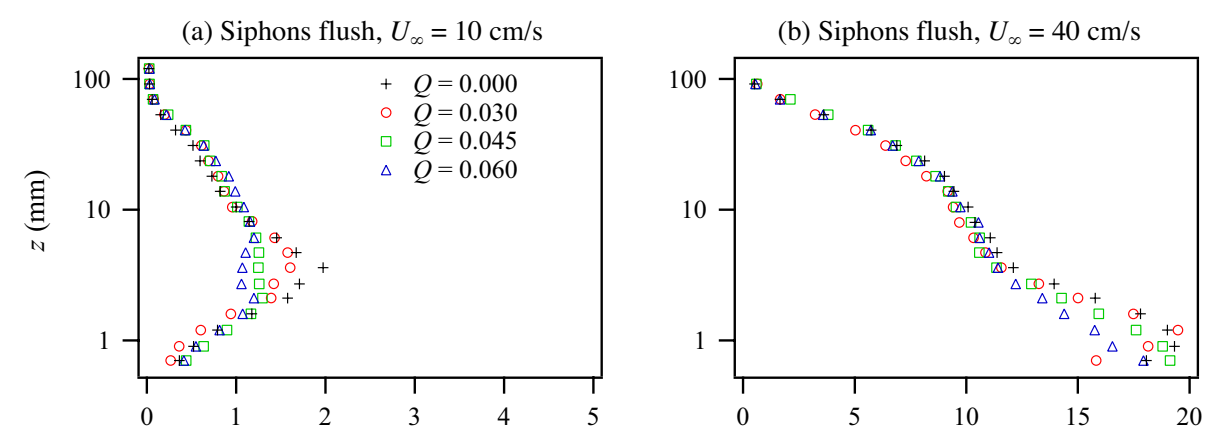

(c) Siphons raised, $U_{\infty}=10 \mathrm{~cm} / \mathrm{s}$

(d) Siphons raised, $U_{\infty}=40 \mathrm{~cm} / \mathrm{s}$
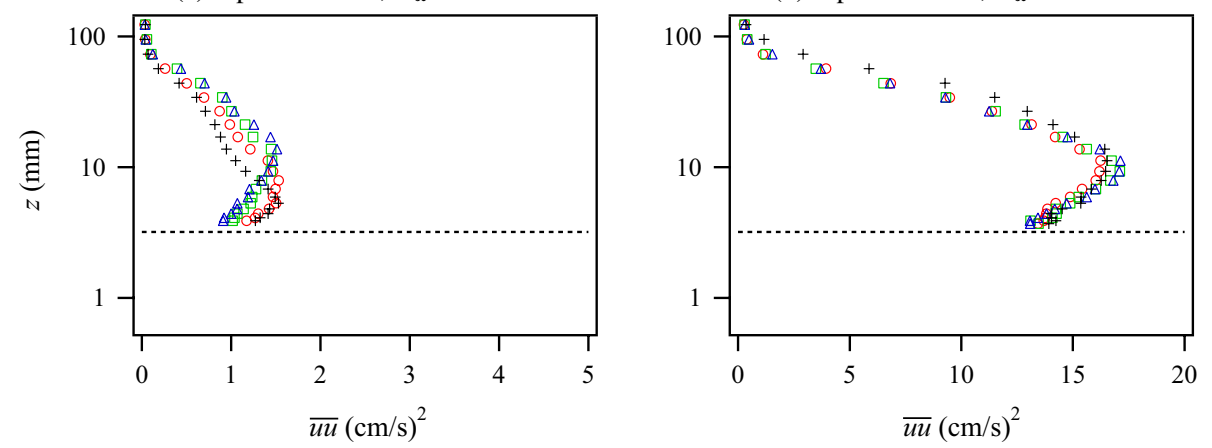

Fig. 13. Effect of clam pumping $Q$ on vertical profiles of streamwise turbulence intensity $\overline{u u}$ for different combinations of free stream velocity $U_{\infty}$ and siphon roughness.

(a) Siphons flush, $U_{\infty}=10 \mathrm{~cm} / \mathrm{s}$

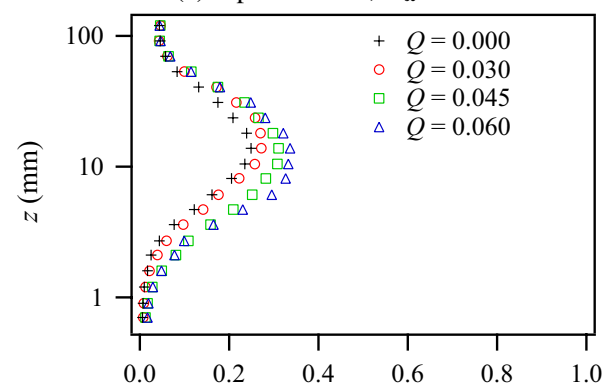

(c) Siphons raised, $U_{\infty}=10 \mathrm{~cm} / \mathrm{s}$

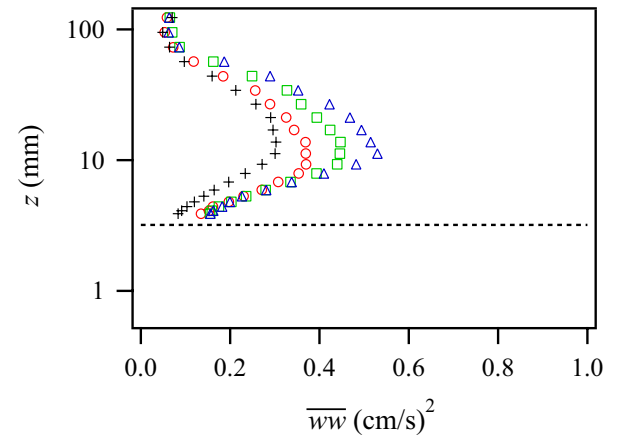

(b) Siphons flush, $U_{\infty}=40 \mathrm{~cm} / \mathrm{s}$

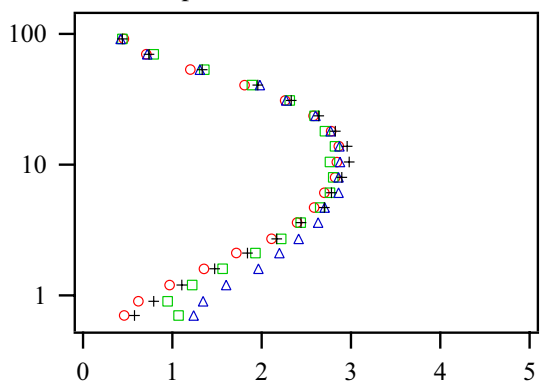

(d) Siphons raised, $U_{\infty}=40 \mathrm{~cm} / \mathrm{s}$

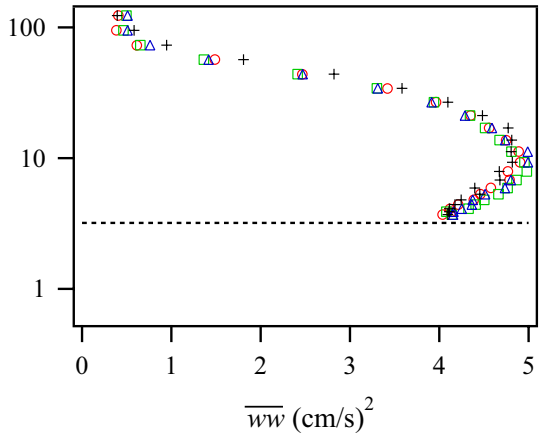

Fig. 14. Effect of clam pumping $Q$ on vertical profiles of vertical turbulence intensity $\overline{w w}$ for different combinations of free stream velocity $U_{\infty}$ and siphon roughness. 
(a) Siphons flush, $U_{\infty}=10 \mathrm{~cm} / \mathrm{s}$

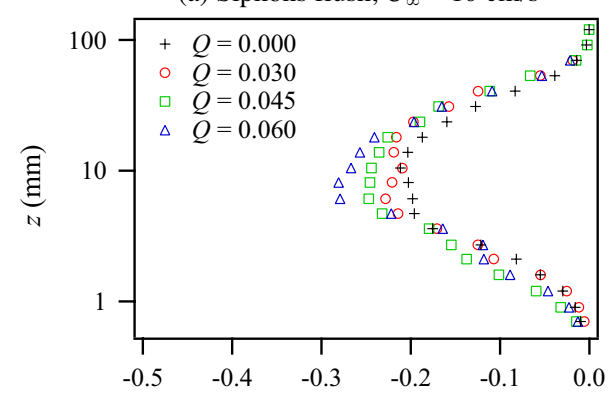

(c) Siphons raised, $U_{\infty}=10 \mathrm{~cm} / \mathrm{s}$

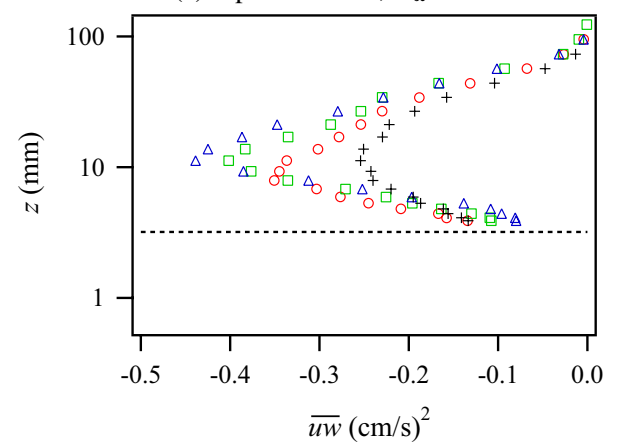

(b) Siphons flush, $U_{\infty}=40 \mathrm{~cm} / \mathrm{s}$

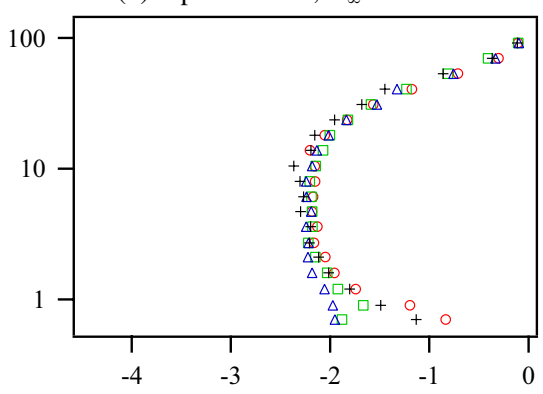

(d) Siphons raised, $U_{\infty}=40 \mathrm{~cm} / \mathrm{s}$

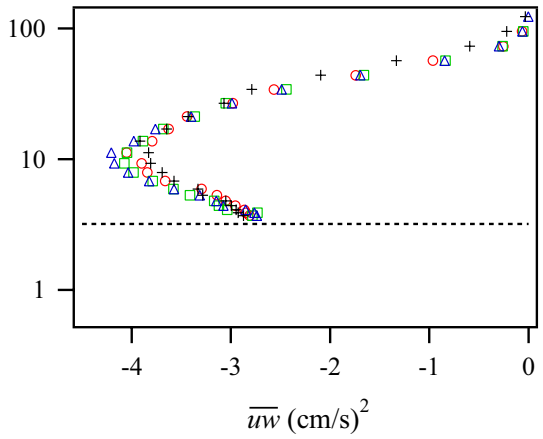

Fig. 15. Effect of clam pumping $Q$ on vertical profiles of Reynolds stress $\overline{u w}$ for different combinations of free stream velocity $U_{\infty}$ and siphon roughness.

(a) Siphons flush, $U_{\infty}=10 \mathrm{~cm} / \mathrm{s}$

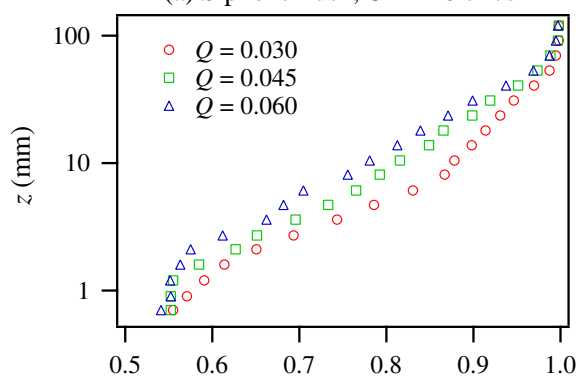

(c) Siphons raised, $U_{\infty}=10 \mathrm{~cm} / \mathrm{s}$

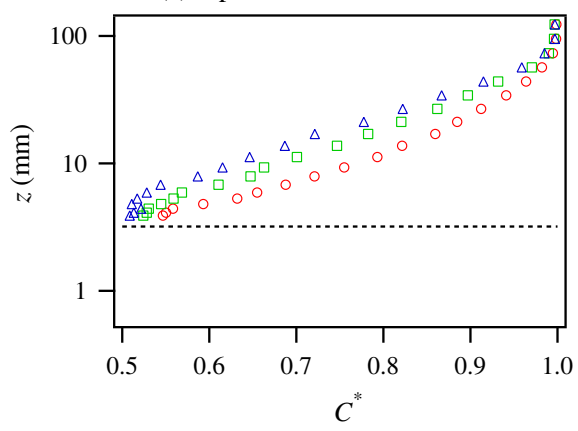

(b) Siphons flush, $U_{\infty}=40 \mathrm{~cm} / \mathrm{s}$

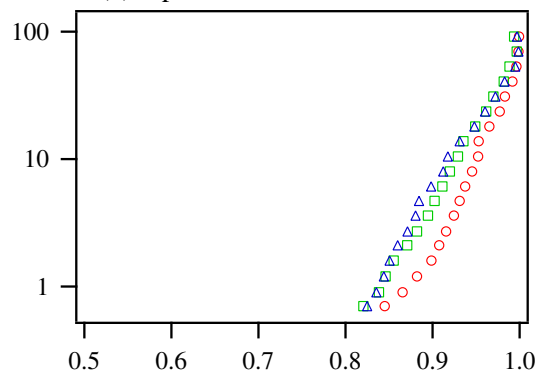

(d) Siphons raised, $U_{\infty}=40 \mathrm{~cm} / \mathrm{s}$

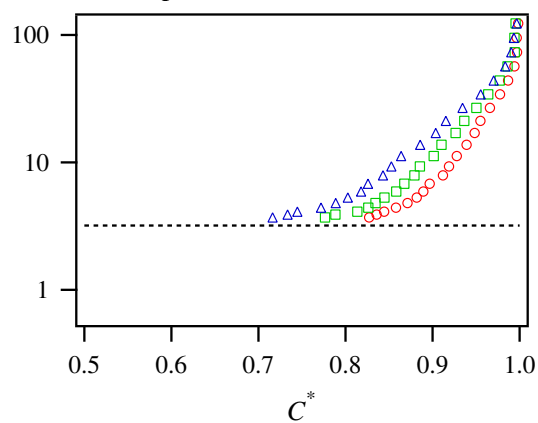

Fig. 16. Effect of clam pumping $Q$ on vertical profiles of mean nondimensional concentration $C^{*}$ for different combinations of free stream velocity $U_{\infty}$ and siphon roughness. 

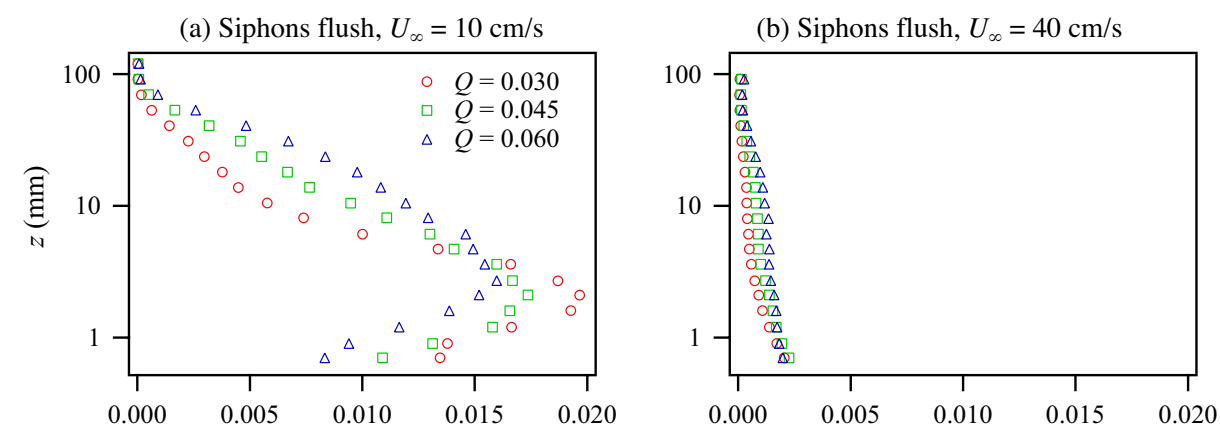

(c) Siphons raised, $U_{\infty}=10 \mathrm{~cm} / \mathrm{s}$

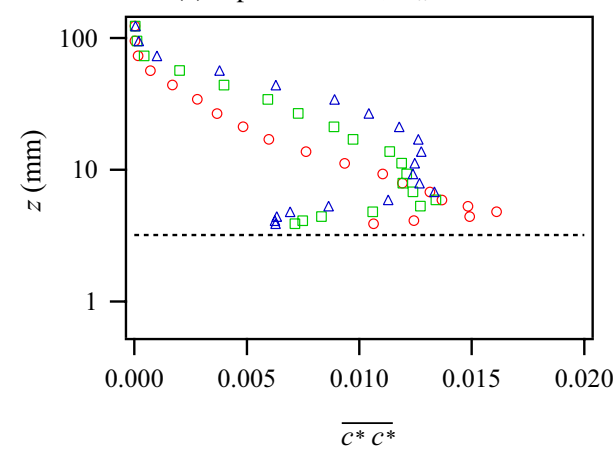

(d) Siphons raised, $U_{\infty}=40 \mathrm{~cm} / \mathrm{s}$

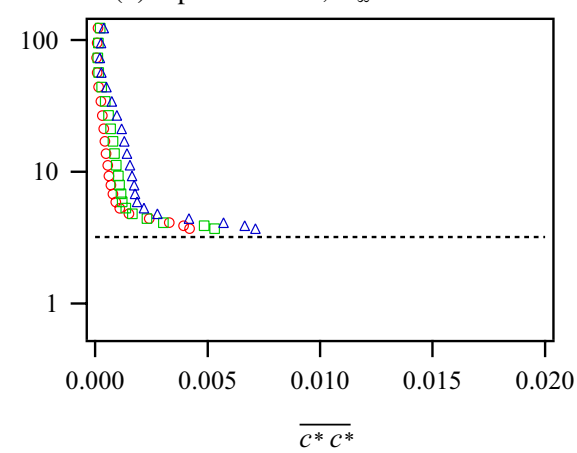

Fig. 17. Effect of clam pumping $Q$ on vertical profiles of nondimensional concentration variance $\overline{c^{*} c^{*}}$ for different combinations of free stream velocity $U_{\infty}$ and siphon roughness.

(a) Siphons flush, $U_{\infty}=10 \mathrm{~cm} / \mathrm{s}$

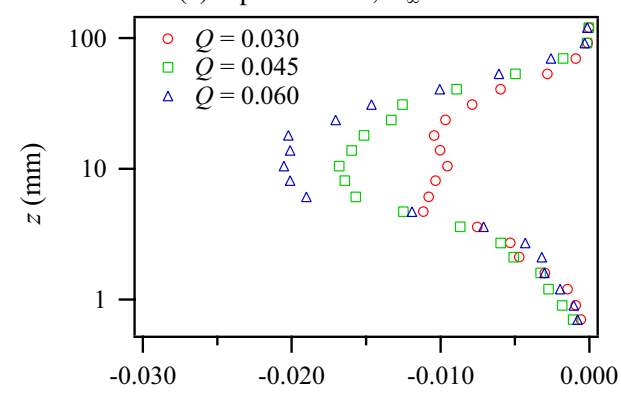

(c) Siphons raised, $U_{\infty}=10 \mathrm{~cm} / \mathrm{s}$

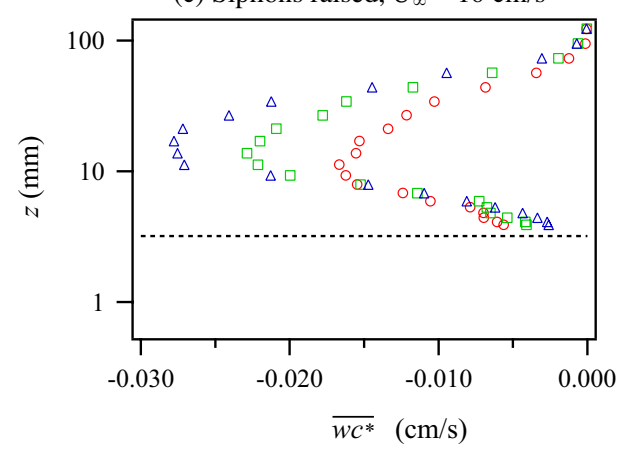

(b) Siphons flush, $U_{\infty}=40 \mathrm{~cm} / \mathrm{s}$

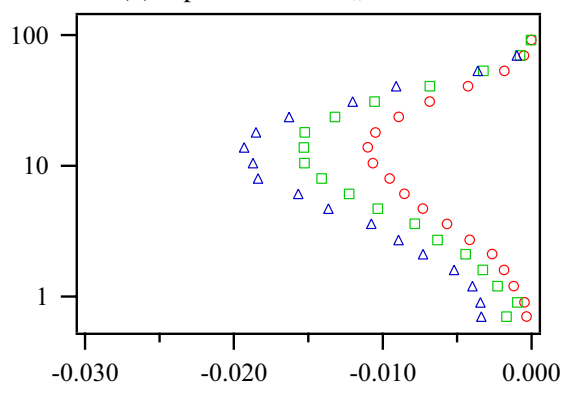

(d) Siphons raised, $U_{\infty}=40 \mathrm{~cm} / \mathrm{s}$

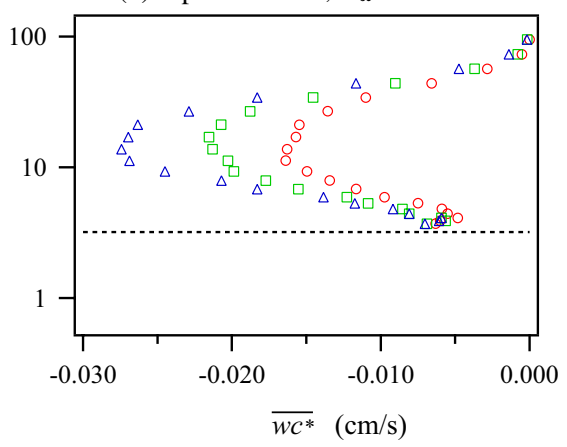

Fig. 18. Effect of clam pumping $Q$ on vertical profiles of vertical scalar flux $\overline{w c^{*}}$ for different combinations of free stream velocity $U_{\infty}$ and siphon roughness. 


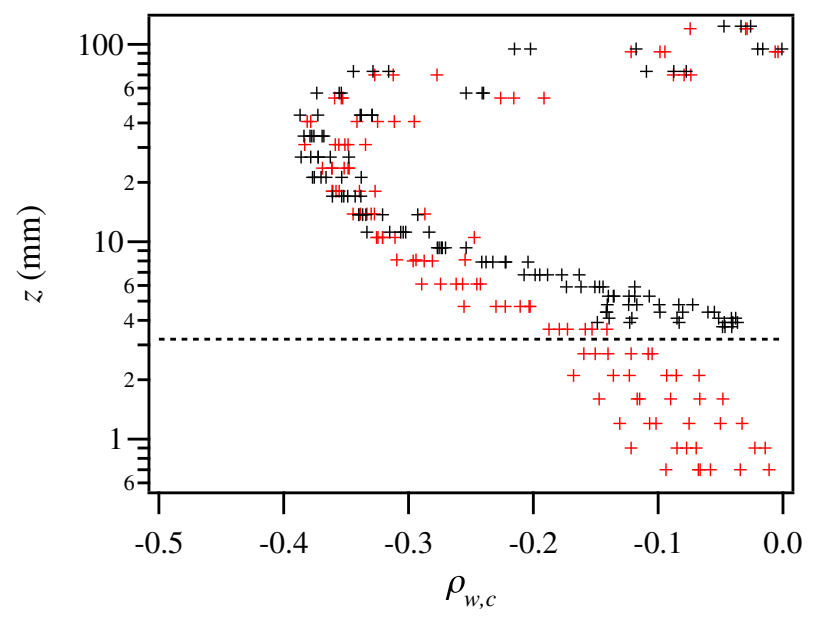

Fig. 19. Vertical profiles of the correlation coefficient $\rho_{w, c}$ for all experimental conditions listed in Table 1. Flush siphon cases are shown in red, and raised siphon cases in black.

In all cases, the mean nondimensional concentration, $C^{*}$, was reduced near the bed (relative to the free stream value of $C^{*}=1$ ) due to the filtering action of the clams (Fig. 16). The reduction was significantly more pronounced for slower flows (a, c), and slightly more so for the raised siphons (c, d). Increased clam pumping also enhanced the concentration reduction, but the effect on the near-bed concentrations was relatively weak. Stronger pumping produced a larger concentration reduction throughout the depth of the boundary layer.

The nondimensional concentration fluctuations, $\overline{c^{*} c^{*}}$, were significantly larger for the slow flow cases relative to the fast flows since there was less mixing to homogenize the concentration field (Fig. 17). For the slow flow cases (a, c), where the excurrent jets penetrated farther into the flow, the peak in the concentration variance was above the wall. The peak moved farther from the wall and decreased in magnitude as pumping increased. For the fast flow cases $(b, d)$, the peak concentration variance was at the tops of the siphons, as the excurrent jets were bent over almost immediately by the crossflow.

Turbulent fluxes of scalar concentration in the vertical direction, $\overline{w c^{*}}$, were always negative, meaning that mass (i.e., phytoplankton) had a net flux towards the bed as a result of near-bed turbulent processes (Fig. 18). The fluxes tended towards zero at the bed and in the free stream, with a peak near $z=10 \mathrm{~mm}$. The magnitude of the peak flux increased approximately linearly with clam pumping, $Q$, and was also significantly larger when the raised siphons were present. A surprising result is that the fluxes were largely insensitive to the mean free stream velocity $U_{\infty}$.
Turbulent scalar fluxes can be expressed as a nondimensional correlation coefficient, defined as

$\rho_{w, c}=\frac{\overline{w c^{*}}}{\sqrt{\overline{w w}} \sqrt{\overline{c^{*} c^{*}}}}$

where $-1 \leq \rho_{w, c} \leq 1$. The correlation coefficient formulation removes the effect of the individual $w$ and $c$ variances, resulting in a true measure of the correlation between the two (Fig. 19). The profiles collapse into a relatively tight band, with a common peak correlation coefficient of approximately -0.38 . Note that the vertical location of the peak correlation coefficient is significantly higher in the flow than the corresponding peak of $\overline{w c^{*}}$.

\section{Discussion}

The results of this study add to a growing body of literature that demonstrates how benthic filter feeders alter characteristics of momentum and scalar concentration fields in the water column. The results share some qualitative similarities with previous studies, despite the fact that different species were involved. Our results show that streamwise turbulence intensities are relatively insensitive to clam pumping and siphon roughness, whereas vertical turbulence intensities increase with pumping rate and roughness. This result is consistent with the increase in turbulent kinetic energy (TKE, the sum of the turbulence intensities in all three directions) demonstrated over beds of shut and open mussels by van Duren et al. (2006). Our measured increases in Reynolds stress due to siphon roughness are qualitatively similar to measurements over mussels by Butman et al. (1994) and van Duren et al. (2006). However, van Duren et al. (2006) did not see any significant change in Reynolds stress for inactive versus actively feeding mussels; our results over model clams show an increase in Reynolds stress as pumping activity increases, especially at slow crossflow velocities. This disparity is likely due to functional differences in the feeding mechanisms between the two species.

In a study over an array of artificial siphon mimics in a natural channel, Jonsson et al. (2005) found that near-bed Chl $a$ concentration depletion increased with shear velocity. This finding went counter to the expectation (shared by the authors of the study) that increased mixing at higher values of $u_{\tau}$ would reduce $\mathrm{Chl} a$ depletion through enhanced vertical mixing. The results of our study indicate that concentration depletion decreases dramatically with flow speed (and thus $u_{\tau}$ - see Fig. 11). However, increases in $u_{\tau}$ due to bed roughness had little effect on concentration depletion, and we did indeed find situations where the concentration depletion was larger for the raised-siphon case as compared to the flush-siphon case, even though $u_{\tau}$ was larger with the siphons raised. It appears that $u_{\tau}$ by itself may not be a reliable metric for concentration depletion. 
When mixing rates are low and phytoplankton replenishment to the bed is poor, the maximum concentration depletion can be located some distance above the bed, due to vertical momentum of the exhalant jets that moves phytoplankton-depleted fluid away from the bed (Sobral and Widdows, 2000; Widdows and Navarro , 2007). It has been suggested that this scalar stratification is beneficial to the filter feeders since it would reduce the degree of re-filtrartation of phytoplankton-depleted water. In the present study, the maximum concentration depletion was always at the lowest measured location. Presumably, this is due to the fact that our flow conditions were always relatively energetic compared to the previous studies.

Our study is the first of its kind to directly measure turbulent vertical mixing of mass above a bed of bivalves. The profiles of $\overline{w c^{*}}$ in Fig. 18 show that the peak turbulent flux of mass to the bed is approximately 50\% larger when the clam siphons are raised. This increase in flux might be expected to decrease the near-bed concentration depletion, but it does not (Fig. 16). One explanation is that the bivalves are able to access higher concentrations by raising their siphons (thus depleting more mass), and this effect overwhelms the roughness-induced increase in turbulent mass flux to the bed. This idea is supported by O'Riordan (1993), who found that incurrent flows had a lower percentage of previously filtered fluid when siphons were raised.

The turbulent mass flux measurements present a detailed picture of how and where mass is transfered to the bed. For our study, the turbulent mass flux goes to zero at approximately $100 \mathrm{~mm}$. This height indicates the extent of the water column that is directly impacted by the presence of the filter feeders. Supply of mass to the bed from regions above this distance would need to rely on large-scale turbulent structures that are not present in our flume. Below $100 \mathrm{~mm}$, mass is actively transported to the bed by organized momentum structures in the presence of the concentration boundary layer. This flux is largest near $z=10 \mathrm{~mm}$. The magnitude of this flux increases with siphonal pumping rate and roughness due to raised siphons. Closer to the bed, the turbulent mass flux $\overline{w c^{*}}$ goes back to zero due to the hydrodynamic requirement that $\overline{w w}$ go to zero at the bed. However, this does not mean that the overall mass flux is being reduced. Instead, the mass flux in the near-bed region is accomplished through mean processes associated with the steady (although spatially inhomogenous) siphonal currents. These fluxes are not captured in $\overline{w c^{*}}$, but have been demonstrated by O'Riordan (1993) and others.

On a final note, there are experimental simplifications in this study that are not representative of real bivalve communities. These include (1) the uniformity of the model bivalve array spacing and geometry, (2) spatially consistent siphon heights, and (3) steady siphonal pumping rates. The effect of these approximations is not known, and future research would be valuable in these areas.

\section{Conclusions}

In this paper we presented a set of measurements in a laboratory flume over a bed of model bivalves. The model bivalves incorporated the effect of roughness in the form of raised clam siphons, incurrent and excurrent flows, and siphonal filtering of ambient scalar mass in the overlaying flow. We measured profiles of velocity and mass concentration for different free stream velocities, clam pumping rates, and siphon positions (flush or raised). The results show that clam pumping rates had a pronounced effect on a wide range of turbulent quantities in the boundary layer. In particular, the vertical turbulent flux of scalar mass to the bed was approximately proportional to the rate of clam pumping. However, the formation of a concentration boundary layer above the clams was only weakly sensitive to the pumping rate. When the bivalves pump more vigorously, the increased turbulent scalar flux of phytoplankton towards the bed mitigates the decrease in concentration of available food. The results demonstrate an important mechanism whereby bivalves are able to effectively filter a broad depth range of the water column rather than just re-filtering the layer of water adjacent to the bed.

Acknowledgements. This work was supported by the National Science Foundation under Grant No. OCE950408. The authors wish to acknowledge work done by C. A. O'Riordan on design and construction of the model clam plates. The manuscript benefited greatly from detailed editing by P. Jumars, and from a review by an anonymous referee.

Edited by: E. Boss

\section{References}

Barrett, T.: Nonintrusive optical measurements of turbulence and mixing in a stably-stratified fluid, Ph.D. thesis, University of California, San Diego, 1989.

Batchelor, G.: Small-scale variation of convected quantities like temperature in turbulent fluid, J. Fluid Mech., 5, 113-133, 1959.

Butman, C. A., Frechette, M., Geyer, W. R., and Starczak, V. R.: Flume Experiments on food-supply to the blue mussel Mytilus-Edulis-L as a function of boundary-layer flow, Limnol. Oceanogr., 39, 1755-1768, 1994.

Carlton, J., Thompson, J., Schemel, L., and Nichols, F.: The remarkable invasion of San Francisco Bay, California (USA) by the Asian clam Potamocorbula amurensis, Mar. Ecol. Prog. Ser., 66, 81-94, 1990.

Cole, B., Thompson, J., and Cloern, J.: Measurement of filtration rates by infaunal bivalves, Mar. Biol., 113, 219-225, 1992.

Crimaldi, J.: Turbulence structure of velocity and scalar fields over a bed of model bivalves, Ph.d. thesis, Stanford University, 1998.

Ertman, S. C. and Jumars, P. A.: Effects of bivalve siphonal currents on the settlement of inert particles and larvae, J. Mar. Res., 46, 797-813, 1988.

Jonsson, P. R., Petersen, J. K., Karlsson, O., Loo, L. O., and Nilsson, S. F.: Particle depletion above experimental bivalve beds: In 
situ measurements and numerical modeling of bivalve filtration in the boundary layer, Limnol. Oceanogr., 50, 1989-1998, 2005.

Koseff, J., Holen, J., Monismith, S., and Cloern, J.: Coupled effects of vertical mixing and benthic grazing on phytoplankton populations in shallow, turbid estuaries, J. Mar. Res., 51, 843-868, 1993.

Larsen, P. S. and Riisgard, H. U.: Biomixing generated by benthic filter feeders: A diffusion model for near-bottom phytoplankton depletion, J. Sea Res., 37, 81-90, 1997.

Monismith, S., Koseff, J., Thompson, J., O'Riordan, C., and Nepf, H.: A study of model bivalve siphonal currents, Limnol. Oceanogr., 35, 680-696, 1990.

O'Riordan, C.: The effects of near-bed hydrodynamics on benthic bivalve filtration rates, Ph.d. thesis, Stanford University, 1993.

O'Riordan, C., Monismith, S., and Koseff, J.: A study of concentration boundary-layer formation over a bed of model bivalves, Limnol. Oceanogr., 38, 1712-1729, 1993.
Sobral, P., Widdows, J.: Effects of increasing current velocity, turbidity and particle size selection on the feeding activity and scope for growth of Ruditapes decussatus from Ria Formosa, southern Portugal, J. Exp. Mar. Biol. Ecol., 245, 111-125, 2000.

O'Riordan, C., Monismith, S., and Koseff, J.: The effect of bivalve excurrent jet dynamics on mass transfer in a benthic boundary layer, Limnol. Oceanogr., 40, 330-344, 1995.

Spalart, P.: Direct simulation of a turbulent boundary layer up to $\operatorname{Re}_{\delta_{2}}=1410$, J. Fluid Mech., 187, 61-98, 1988.

Tennekes, H. and Lumley, J.: A First Course in Turbulence, The MIT Press, Cambridge, 1972.

van Duren, L. A., Herman, P. M. J., Sandee, A. J. J., and Heip, C. H. R.: Effects of mussel filtering activity on boundary layer structure, J. Sea Res., 55, 3-14, 2006.

Widdows, J. and Navarro, J. M.: Influence of current speed on clearance rate, algal cell depletion in the water column and resuspension of biodeposits of cockles (Cerastoderma edule), J. Exp. Mar. Biol. Ecol., 343, 44-51, 2007. 